\title{
Integrating a Trauma-informed Care Perspective in Baccalaureate Social Work Education: Guiding Principles
}

\author{
Matthew Lorenzo Vasquez \\ Shamra Boel-Studt
}

\begin{abstract}
Over the past decade, there has been substantial growth in empirical evidence supporting that proper assessment and treatment of trauma using evidence-based practices can effectively reduce a wide range of symptoms in both children and adults. Given the complex nature of trauma treatment, trauma-based educational programming in social work is most commonly found at the graduate level. Yet, to date, there has been little discussion calling for the inclusion of trauma content in BSW education. In this paper, we examine the current state of trauma-content inclusion in social work education, and offer a guiding framework for integrating core trauma content into the BSW curriculum that is based on the core principles of trauma-informed care.
\end{abstract}

Keywords: Trauma; trauma-informed care; baccalaureate social work

Over the past decade, there has been mounting evidence for assessment and treatment methods capable of effectively identifying and reducing a wide range of trauma symptoms in pediatric (de Arellano et al., 2014; Schneider, Grilli, \& Schneider, 2013) and adult samples (Ehlers et al., 2010; Rubin \& Springer, 2009). Subsequently, trauma-focused interventions have grown in popularity and are increasingly being recognized as a standard form of treatment for trauma-affected individuals.

Given the complex nature of trauma treatment and the numerous issues that can arise concerning client-safety, trauma-based educational programming is most commonly found at the graduate level (Courtois \& Gold, 2009). Indeed, a growing number of MSW programs have begun integrating trauma content into their curriculum (Abrams \& Shapiro, 2014; Bussey, 2008; Strand, Abramovitz, Layne, Robinson, \& Way, 2014). Yet, to date, there has been little discussion calling for the inclusion of trauma content in BSW education (McKenzie-Mohr, 2004). With BSWs often having "first contact" with various client populations, including those who have been chronically maltreated and traumatized, it is necessary for BSW programs to include content into their curriculum that provides students with an understanding of trauma, its treatment, and the ways in which service organizations can best serve traumatized individuals. In this paper, we examine the current state of trauma-content inclusion in social work education, and offer guiding principles for integrating core trauma content into the BSW curriculum that is based on the principles of trauma-informed care.

\section{Definition and Prevalence of Trauma}

A variety of definitions of trauma have been presented in the literature. In an effort to develop a common conceptualization that is applicable to both practitioners and researchers, the Substance Abuse and Mental Health Services Administration (SAMHSA;

Matthew L. Vasquez, PhD, LMSW is Assistant Professor, Department of Social Work, University of Northern Iowa, Cedar Falls, IA 50614, Shamra Boel-Studt, PhD, is Assistant Professor, College of Social Work, Florida State University, Tallahassee, FL 32306. 
2014) conducted an extensive review of existing definitions followed by a review from an expert panel to propose the following definition:

Individual trauma results from an event, series of events, or set of circumstances that is experienced by an individual as physically or emotionally harmful or lifethreatening and that has lasting adverse effects on the individual's functioning and mental, physical, social, emotional, or spiritual well-being. (p.7)

Prevalence of exposure to traumatic events is high among children and adults in the United States. Studies have shown that approximately $70-80 \%$ of children and adolescents (ages 2-17) were exposed to at least one type of victimization in their lifetime and 66\% had been exposed to multiple types of victimization including child maltreatment, attempted kidnapping, peer/sibling victimization, domestic violence and crime in their communities (Copeland, Keeler, Angold, \& Costello, 2007; Turner, Finkelhor, \& Ormrod, 2010). In a nationally representative survey of adults, $89.7 \%$ reported having been exposed to at least one traumatic event with an average exposure to 3.30 different types of events (Kilpatrick et al., 2013). Similar rates of traumatization have been found in other studies using national and internationally representative samples (see Breslau et al., 1998; Frans, Rimmö, Åberg \& Fredrickson, 2005; Stein, Walker, Hazen, \& Forde, 1997; Vrana \& Lauterbach, 1994).

\section{Trauma Studies in Social Work Education}

Numerous studies highlight the impact of trauma on long-term health and mental health functioning (Dong et al., 2004; Felitti el al., 1998), including the high rates of social service use among these populations (Elhai, North, \& Frueh, 2005; Jennings, 2008; Solomon \& Davidson, 1997). Consequently, there is a growing sentiment that the inclusion of traumafocused content should be presented in helping professional degree programs (Courtois \& Gold, 2009; Marlowe \& Adamson, 2011; Strand et al., 2014). Yet, Courtois (2002) notes that the specialized study of traumatic stress has yet to be fully included in social science educational programs. Courtois (2002) cautions:

This lack of inclusion has the effect of preventing traumatized individuals from getting needed services from professional and lay personnel who are knowledgeable about trauma, trauma response, and their particular role. In turn, it has also had the potential for creating more distress in traumatized individuals, in their loved ones, and in even those charged with providing help. Thus, the need for this information and its inclusion in professional curricula, is not casual and is, in fact urgent. (p. 53)

This sense of urgency has not gone unnoticed within the field of social work. In 2012, the Task Force on Advanced Social Work Practice in Trauma published guidelines on how to integrate trauma-focused content into social work programming (CSWE, 2012, Advanced Social Work Practice in Trauma). These guidelines are based on the 10 Education and Policy Accreditation Standards (EPAS) core competencies that were set forth by CSWE in 2008, and include individual, family, organizational, and community-based recommendations for advanced social work practice in trauma. The authors are clear that these guidelines are meant for integration in MSW-level programming. As such, there is ample discussion of activities that concern assessment, diagnosis and clinical intervention, 
which are practice behaviors often associated with advanced social work practice. Thus, it could be argued that the current state of social work education views the inclusion of trauma-related content as best-suited for the graduate level.

\section{Graduate Social Work Education in Trauma}

Currently, there are several graduate-level trauma certificate programs offered at schools of social work throughout the nation. Many of these programs have a clinical emphasis, and include specific training in interventions like trauma-focused cognitive behavioral therapy (TF-CBT), crisis/disaster intervention models, and trauma-informed care (see Bussey, 2008). These programs may be included as part of the graduate curriculum, or housed within continuing education programs, with graduate students and practicing social workers being able to participate. Many of these programs are relatively new and, therefore, have yet to be evaluated.

One recent approach to integrating trauma-related content into graduate social work education has come from the National Child and Traumatic Stress Network's (NCTSN) Core Curriculum on Childhood Trauma (CCCT; Layne et al., 2011). The CCCT's aim is to advance the knowledge of graduate students and current working professionals on the core concepts of psychological trauma, which can then prepare them for more advanced training in evidence-based trauma treatment (EBTT). The CCCT consists of a five-tier conceptual framework, and uses problem-based learning (such as the use of real case vignettes) along with the use of facilitators who hold extensive clinical experience in trauma-related practice. In a large-scale evaluation of a modified version of the CCCT, the Core Concepts in Child and Adolescent Trauma, in graduate schools of social work researchers found that students experienced significant pre-posttest increases in selfreported confidence in applying the core concepts of trauma (Layne et al., 2014). The researchers also found that other students who participated in the "gold standard plus" educational model, which included the CCCT course, training in EBTT, and implementation of the EBTT in field placement, experienced significant pre-posttest increases in self-reported conceptual and field readiness. The CCCT constitutes one of the first comprehensive initiatives to promote trauma training for MSW students, and may reflect a growing trend for schools of social work to implement more structured approaches to offering trauma-based programming.

There is also a growing discussion of how to safely and effectively present trauma content to graduate social work students. Students with trauma histories who are exposed to trauma-related content, whether in the classroom or during field placement, have the potential to experience vicarious trauma, or to be re-traumatized by material that reflects past experiences (Carello \& Butler 2014, 2015; Didham, Dromgole, Csiernik, Karley, \& Hurley, 2011; Knight, 2010). This can be highly disruptive to student learning (Miller, 2001), as those who lack awareness of the severity of their past trauma can draw upon intense, maladaptive patterns of coping when exposed to course content that triggers prior traumas (Etherington, 2000). In response to this issue, recommendations have been offered on how to make the classroom environment a safe place for graduate students by presenting content that aids in the reduction of secondary traumatic stress (O'Halloran \& O'Halloran, 
2001; Shannon, Simmelink, Im, Becher, \& Crook-Lyon, 2014) and vicarious trauma (Dane, 2002).

\section{Baccalaureate Social Work Education in Trauma}

Although the inclusion of trauma-related content in graduate level curricula has grown in popularity, the literature on the inclusion of trauma content in BSW education is limited. McKenzie-Mohr (2004) calls for the inclusion of trauma-focused content in the BSW curriculum due to the high likelihood that most graduates will obtain employment in organizations that provide services to traumatized and/or oppressed individuals. Breckenridge and James (2010) discuss the rationale for their development of a BSW course that emphasized multifaceted approaches to addressing trauma that encourages students to view treatment as including individual, group, community, and policy-based interventions. Finally, Farchi, Cohen, and Mosek (2014) describe their development of an Israeli stress and trauma studies (STS) program. The STS was a supplementary curriculum to an undergraduate social work program in which students were trained to act as psychological first responders to those who had just experienced traumatic events with the aim of preventing the development of trauma symptoms.

Currently, there is no recommended model for infusing trauma-related content across the BSW curriculum like the one provided by the Task Force on Advanced Social Work Practice in Trauma (CSWE, 2012) for MSW programming. The reasons behind this lack of emphasis are not entirely clear. One reason could be, as previously discussed, the potential for students to experience duress when exposed to trauma content. MSW students may be viewed as having more life and/or work experience than BSW students, and therefore, perceived as mature enough to manage the sensitive nature of the content (Bell, Kulkarni, \& Dalton, 2003; Neumann \& Gamble, 1995).

Another reason may be the perception that the study of trauma is inherently complex and clinical in nature (see CSWE, 2012), and therefore best suited for graduate-level social work programming. The CSWE Educational Policy and Accreditation Standards (EPAS; 2015) state that MSW programs help students to "identify the specialized knowledge, values, skills, cognitive and affective processes, and behaviors that extend and enhance the nine Social Work Competencies and prepare students for practice in the area of specialization" (p.12). Although there is no discussion of what constitutes specialized practice, the study of trauma and its treatment may be viewed as a primarily clinical endeavor, which is often synonymous with advanced or specialized practice. Thus, the structure of graduate social work education, with its strong emphasis on field education, may be deemed as best-suited to help students learn the theoretical concepts related to trauma and then to apply them during field placements. Due to BSW education being rooted in generalist practice, which does not typically include content on clinical or other specialized forms of practice, there may be a perceived difficulty in connecting traumarelated content with the BSW curriculum.

With the high likelihood of BSW students finding employment with organizations that serve traumatized individuals, we advocate for the inclusion of trauma-related content in the BSW curriculum. Such content should provide students with an understanding of the 
ways in which trauma affects individuals, families, and communities, along with an understanding of how social service organizations' practices and policies can impact service delivery and their clients who have experienced trauma. One practice model that may offer an effective way to integrate a broad spectrum of trauma content into a generalist model of social work practice is trauma-informed care.

\section{Trauma-Informed Care}

In recent years, there has been a growing movement for trauma-informed practices to be implemented across a broad spectrum of service settings and client populations, such as in child welfare (Ko. et al., 2008), in-patient psychiatric settings (Azeem, Aujla, Rammerth, Binsfeld, \& Jones, 2011; Huckshorn, 2004; Regan, 2010), with inmates (Levenson, Willis, \& Prescott, 2014), and the homeless (Hopper, Bassuk, \& Olivet, 2009; McKenzie-Mohr, Coates, \& McLeod, 2012). Generally, in trauma-informed care settings, staff a) assess for and understand the impact of trauma on their clients, b) provide clients the knowledge and skills needed for recovery, and c) actively address treatment barriers and service delivery practices that may lead to potential re-traumatization (Elliott, Bjelajac, Fallot, Markoff, \& Reed, 2005; Gatz et al., 2007). Depending on the specific needs of the client population, staff may be trained in how to establish and maintain safety and therapeutic relationships, de-escalation techniques, and strengths and empowerment models of client-care and case management (Azeem et al., 2011; Borckardt et al., 2011; Elliott et al., 2005).

A trauma-informed care system also serves to support and maintain trauma-specific treatment approaches, which are "designed to treat the actual sequelae of sexual or physical abuse trauma" (Jennings, 2008, p. 10). These approaches can include psychoeducation, therapies designed to address trauma and its accompanying symptoms (e.g., cognitive therapies, desensitization therapies, prolonged exposure), emotional regulation and social skill-building, enhancing resiliency, and psychotropic medication management (Cohen, Mannarino, Berliner, \& Deblinger, 2000; Jennings, 2008; NCTSN, 2007). This dualapproach to service delivery provides all those involved in client cases (e.g., case managers, clinicians, and administrators) with a common understanding and language surrounding the impact of trauma and its treatment. Such an environment allows clients to safely and confidently engage in trauma-based therapy without the fear of potential mismanagement of their care by those uninformed about their specific needs.

At the crux of trauma-informed care is the understanding that service organizations need to be consistent in the ways that they engage clients who have experienced trauma, while being flexible in responding to their individual needs (Prescott, Soares, Konnath, \& Bassuk, 2008). Striking this balance requires staff to continuously reflect upon and evaluate both personal and organizational forms of practice, and to make changes accordingly. We propose that the skills and competencies needed to effectively engage in this type of practice closely align with those found in generalist social work practice. Therefore, the BSW curriculum, which is based on a generalist model, serves as an ideal platform to present principles of trauma-informed care. In the following sections, we present a comprehensive trauma-informed care framework that educators can use to guide the infusion of trauma-related content into their BSW curriculum. 


\section{Method}

To identify core content areas that could be integrated into the BSW curriculum, we conducted a literature search to identify common principles found in trauma-informed care practice frameworks across a variety of professional disciplines. Focusing on frameworks that were published since 2000, we searched Google Scholar, Academic Search Complete and Elite, and PsychINFO. Additionally, we searched the internet using Google to identify frameworks published on organizational and government websites and other reputable nonacademic literary sources (e.g., NCTSN, SAMHSA, National Center for Biotechnology Information). We used a combination of the search terms: trauma, trauma-informed care, approach, perspective, principles, and framework.

To begin, each author conducted a separate literature search to identify traumainformed frameworks. In total 13 frameworks were found using our search criteria. Each framework was then separately reviewed for common practice principles by both authors and compared for agreement. Initially, 19 common principles were identified. In a second review, we collapsed seven of the principles into broader categories in which they were closely aligned (e.g., empowerment, choice, autonomy). We further applied a selection criterion in which a principle had to have been present in at least four frameworks to be considered 'common'. This was based on our finding that a principle appeared at least four times and below that range, the identified principles or guidelines were sporadic, appearing only once or twice. At that point, we reached $100 \%$ agreement on the remaining principles. This level of agreement was facilitated by the high level of consistency in the stated principles and the language used across frameworks. The remaining nine principles are summarized in Table 1, and represent the most commonly identified principles of traumainformed care practice across the fields of mental health, social work, nursing, child welfare, and criminal justice. In the following section, we present these nine principles, along with recommendations for integration within a generalist BSW curriculum. Similar to the Task Force on Advanced Social Work Practice in Trauma (CSWE, 2012), our framework should serve as a guide for social work educators. 
Table 1. Common Principles Identified Across Trauma-Informed Care Practice Frameworks

\begin{tabular}{|c|c|c|c|c|c|c|c|c|c|}
\hline Source & $\begin{array}{l}1 \text { Trauma } \\
\text { Knowledge }\end{array}$ & $\begin{array}{c}2 \text { Trauma } \\
\text { Screening \& } \\
\text { Assessment }\end{array}$ & $\begin{array}{c}3 \text { Safety \& } \\
\text { Minimize Re- } \\
\text { victimizing }\end{array}$ & $\begin{array}{l}4 \text { Empowerment } \\
\text { \& Self- } \\
\text { Determination }\end{array}$ & $\begin{array}{l}5 \text { Identifying } \\
\text { Strengths }\end{array}$ & $\begin{array}{l}6 \text { Cultural } \\
\text { Competency }\end{array}$ & $\begin{array}{c}7 \text { Healthy } \\
\text { Relationships }\end{array}$ & $\begin{array}{l}8 \text { Emotion } \\
\text { Regulation }\end{array}$ & 9 Self-Care \\
\hline Bath (2008) & & & $\mathrm{X}$ & & & & $\mathrm{X}$ & $X$ & \\
\hline Bloom \& Sreedhar (2008) & & & $\mathrm{X}$ & $X$ & $\mathrm{X}$ & & $\mathrm{X}$ & $\mathrm{X}$ & \\
\hline Covington et al. (2008) & $\mathrm{X}$ & & $\mathrm{X}$ & $\mathrm{X}$ & $\mathrm{X}$ & & $\mathrm{X}$ & $\mathrm{X}$ & \\
\hline Elliot et al. (2005) & $\mathrm{X}$ & $\mathrm{X}$ & $\mathrm{X}$ & $\mathrm{X}$ & $\mathrm{X}$ & $\mathrm{X}$ & $\mathrm{X}$ & & \\
\hline Guarino et al. (2009) & $\mathrm{X}$ & $\mathrm{X}$ & $\mathrm{X}$ & $\mathrm{X}$ & $\mathrm{X}$ & $\mathrm{X}$ & $\mathrm{X}$ & & $\mathrm{X}$ \\
\hline $\begin{array}{l}\text { Huckshorn (2004) } \\
\text { Huckshorn et al. (2005) }\end{array}$ & $X$ & & $X$ & $X$ & & & & & \\
\hline $\begin{array}{l}\text { Harris \& Fallot (2001) } \\
\text { Fallot \& Harris (2001) }\end{array}$ & & $X$ & X & $X$ & & & $X$ & & \\
\hline Kinniburgh et al. (2005) & & & $\mathrm{X}$ & & & & $X$ & $\mathrm{X}$ & \\
\hline $\begin{array}{l}\text { McManus \& Thompson } \\
\text { (2008) }\end{array}$ & $X$ & & $X$ & $X$ & $X$ & & & & \\
\hline NCTSN (2007) & $\mathrm{X}$ & $\mathrm{X}$ & $\mathrm{X}$ & & & $\mathrm{X}$ & $\mathrm{X}$ & $\mathrm{X}$ & $\mathrm{X}$ \\
\hline Prescott et al. (2008) & $\mathrm{X}$ & $\mathrm{X}$ & $\mathrm{X}$ & $\mathrm{X}$ & $\mathrm{X}$ & $\mathrm{X}$ & $\mathrm{X}$ & & $\mathrm{X}$ \\
\hline Saakvitne et al. (2000) & $\mathrm{X}$ & & & $\mathrm{X}$ & $\mathrm{X}$ & & $\mathrm{X}$ & & $\mathrm{X}$ \\
\hline SAMSHA (2014) & & & $\mathrm{X}$ & $\mathrm{X}$ & & $\mathrm{X}$ & $\mathrm{X}$ & & \\
\hline
\end{tabular}

Note. NCTSN = National Child Traumatic Stress Network; SAMSHA = Substance Abuse and Mental Health Service Administration. 


\section{Recommendations for Integrating Trauma-Informed Care Principles in the BSW Curriculum}

\section{Principle 1: Trauma Knowledge}

Trauma knowledge is defined as having an understanding of how traumatic events impact individual's development, health, well-being and coping abilities (Guarino, Soares, Konnath, Clervil, \& Bassuk, 2009; NCTSN, 2007). Having this foundational awareness is an essential first step for social workers to effectively work with traumatized populations and understand the various ways in which trauma can affect clients' cognitive, emotional, behavioral and social functioning. One such example would be recognizing that many trauma symptoms stem from physiological responses within the body (e.g., hyperarousal and activation of the sympathetic nervous system), and that maladaptive coping behaviors (e.g., physical and verbal aggression, substance abuse, self-harm) are often used to manage these symptoms. Understanding this can help social workers to more accurately assess clients and the symptoms they may be presenting with (Covington, Burke, Keaton, \& Norcott, 2008; McManus \& Thompson, 2008; Prescott et al., 2008). Post-traumatic stress symptoms or maladaptive coping behaviors often interfere with healthy functioning in other domains of life and can make seeking assistance, whether voluntarily or mandated, from a service organization seem "fraught with danger" (Elliot et al., 2005, p. 463). Understanding the types of duress traumatized clients may be experiencing when seeking services can aid social workers in developing professional practices and service environments that promote physical and emotional safety and reduce the risk of retraumatization (McManus \& Thompson, 2008).

Education on trauma has largely focused on understanding individual trauma (Audergon, 2004; Bell et al., 2003), yet trauma can also be experienced collectively and impact functioning within larger community (Nytagodien \& Neal, 2004) and organizational systems (Bloom, 2010). Social services organizations often operate under conditions of chronic stress (Bloom, 2010) including working with traumatized and challenging clients, limited resources, workforce issues, and political and social scrutiny. The accumulation of chronic stress can lead to high rates of burn-out, employee turnover, mission drift and a loss of clarity in the values and goals that drive the organization (Bloom \& Sreedhar, 2008). Similarly, communities can also be deeply impacted by trauma and become entrapped in a traumatized culture. Individuals experience and cope with trauma within the context of a community (Kahn, 2003) and communities as a whole can experience collective trauma due to natural disasters, violence, poverty or other events (SAMSHA, 2014). Trauma-affected organizations and communities can manifest traumatic stress symptoms characterized by hypervigilance, fear, mistrust, and withdrawal. Because the community and organizational contexts provide the backdrop in which micro and macro level interventions are delivered, they are an integral part of any intervention, whether it involves providing direct care services within an agency, community outreach work, or organizational practice.

Integrating trauma content in the BSW curriculum could enhance students' understanding of the impact of trauma on individuals, families, groups, communities and 
organizations. Courtois and Gold (2009) recommend presenting trauma in undergraduate curricula as "a normal and frequent occurrence in human history and as an influential, but as yet not fully recognized, factor in human development" (p. 18). They further recommend highlighting how traumatic experiences can engender strength and resiliency (posttraumatic growth). As such, courses like Human Behavior in the Social Environment (or its equivalent) that focus on developmental theories and the specific needs of people across the lifespan could easily incorporate content that discusses how traumatic experiences can affect multiple domains of functioning and development. Research courses could expand on this content by providing BSW students opportunities to review current empirical studies on trauma, and macro-oriented courses could highlight how organizational structures, community initiatives, and policy decisions can impact clients who use certain services.

\section{Principle 2: Trauma Screenings and Assessments}

In addition to understanding the ways in which trauma can impact clients, it is equally important to screen and assess clients for past and current trauma experiences so that more individualized, holistic treatment planning can occur (Harris \& Fallot, 2001). Fallot and Harris (2001) define trauma screening as "brief, focused inquiry to determine whether an individual has experienced specific traumatic events" (p. 24). Trauma screenings aid in identifying exposure to traumatic experiences or events, whether the client is currently in danger or exhibiting trauma symptoms, and are used to determine if a referral for a more in-depth trauma assessment is needed (Conradi, Wherry, \& Kisiel, 2011; Fallot \& Harris, 2001). Screening can also encourage service providers to see clients from a perspective of how they have been hurt, rather than seeing only their presenting problems resulting in greater compassion and understanding of the client's presenting issues and the surrounding circumstances.

The value that trauma-informed care places on screening and assessment practices that identify the ways in which trauma has affected a client's current functioning is reflective of generalist social work practice's use of the person-in-environment framework (CSWE, 2015). As such, many undergraduate programs of social work likely already provide content that emphasizes the importance of screening and assessment, the use of ecological and systems models, and the identification of strengths along with needs. Thus, the inclusion of how these frameworks and practice behaviors can better serve clients who have experienced trauma could be a relatively seamless integration. We do not necessarily advocate training BSW students on how to conduct specific types of standardized trauma screening tools and assessments, as this may be too specific of an activity for some generalist programs. However, universal trauma screening is often done during the period of initial contact with a client and often by bachelor's level service providers. Indeed, some of the most widely used trauma screening tools require bachelor's level education and training (e.g., Child Abuse and Neglect Scale - Trauma Version; Kisiel, Fehrenbach, Small, \& Lyons, 2009; Trauma Symptom Checklist, Briere, 2005). Thus, the decision to incorporate training on specific screening and assessment tools can be left to the discretion of individual BSW programs. 


\section{Principle 3: Client Safety and Minimizing Re-traumatization}

The principle of developing and sustaining organizational practices that promote client safety and limit the possibility of re-traumatization was found among all of the identified trauma-informed care frameworks. The importance of such a principle cannot be overstated; it represents the core of trauma-informed care, serving as a prerequisite to providing other elements of trauma-informed services. Safety, in the context of individual and organizational service delivery, is multi-faceted, with many elements that need to be considered by helping professionals (Bath, 2008). For example, professional qualities such as consistency, reliability, availability, honesty, and transparency in helping professionals can engender a safe and therapeutic environment for clients. Furthermore, a demonstrated tolerance for the range of intensity of reactions by trauma survivors can aid in developing rapport and feelings of trust (Guarino, Rubin, \& Bassuk, 2007; Prescott et al., 2008). Client safety can be established through case management practices (NCTSN, 2007) that include assessing the potential for re-traumatization (e.g., does an abusive partner or parent have access to the client?), providing contact information for shelters, food pantries, crisis hotlines, and establishing legal protections such as restraining and protection orders. Implementing organizational practices that are sensitive to the individual needs of traumaaffected clients can also foster a sense of client safety. For example, a domestic violence shelter for women who have likely experienced abuse by male perpetrators, may have policies limiting the type and duration of contact male staff have with the clients as a way to protect clients from becoming triggered or experiencing symptoms of hyperarousal and fear (Prescott et al., 2008).

Integrating or enhancing content in existing BSW curricula that exemplifies how building trust, establishing rapport, adhering to ethical and professional standards of practice, and case management, can increase BSW students' preparedness to engage in practices that promote a sense of safety in trauma survivors. Social work educators may choose to approach this in many ways, including through having students role play the intake and assessment/screening processes with trauma-affected clients, practicing communication styles, both verbal and non-verbal, that allow students to develop a skillbase and sense of self-efficacy in their future work with trauma survivors, and through the use of case-vignettes that require students to assess the current functioning of a client and then to provide their recommendations for building safety. Finally, additional content outlining the importance of identifying how organizational practices and policies promote (or possibly restrict) the development of client safety may prepare future social workers to proactively assess and advocate for organizational practices that ensure clients' safety and needs are being met.

\section{Principle 4: Client Empowerment and Self-Determination}

Organizations that serve clients who have experienced traumatic victimization (e.g., intimate partner violence, and physical, emotional, and/or sexual abuse) understand that the inherent nature of these experiences are often rooted in a sense of coercion, powerlessness, and a loss of control (Dutton \& Goodman, 2005; Gershuny \& Thayer, 1999; Najavits, Sonn, Walsh, \& Weiss, 2004). As such, recognizing and addressing power imbalances between the organization/staff and client can help to lessen the likelihood of 
re-traumatization and foster a sense of safety and trust in the client. For example, shareddecision making surrounding client treatment options and goal setting is strongly encouraged in both policy and practice (SAHMSA, 2014). Allowing trauma survivors to have a voice in their own treatment and goal development will increase motivation to engage in services, which may result in better outcomes (Prescott et al., 2008). In instances where the social worker believed the client to be making a poor choice, every effort is made to understand the perspective of the client in addition to providing clarifying information in the hopes of reaching a mutual goal (Elliot et al., 2005).

The principles of client self-determination and empowerment constitute some of the foundations by which contemporary generalist social work practice is formed (see KirstAshman, \& Hull, 2014; Miley, O'Melia, \& DuBois, 2013). Incorporating these principles within the context of working with traumatized populations into BSW programs of study should be relatively seamless, as many programs likely already include such content. BSW programs may consider adding content on how to engage in practices that promote client empowerment and self-determination during the initial contact with a client who has experienced trauma during screenings and assessments, and in more long-term service relationships to demonstrate how such an approach can be implemented across a variety of practice situations.

\section{Principle 5: Client and Organizational Strengths Identification}

An integral part of client empowerment and self-determination (principle 4) is the identification of client strengths (SAMSHA, 2014). In repeated or long-term cases of trauma, individuals may perceive their current reality as one where they have little control over what happens to them. Therefore, daily stressors and problems may seem insurmountable. Identifying client strengths can help lessen this sense of powerlessness, and promote a sense of empowerment, self-efficacy, and resiliency, all of which can aid in the attainment of therapeutic goals (McManus \& Thompson, 2008; NCTSN, 2007).

The identification of strengths can also be applied to service organizations. In discussing the steps of the Sanctuary Model, Bloom and Sreedhar (2008) point out the need for staff members to engage in discussions that identify the strengths, vulnerabilities, and conflicts within an organization. These open discussions can provide a shared analysis of the organizations' structure, current functioning, and quality of service delivery. Such an approach may prove useful in building cohesiveness among staff within an organization, and can highlight positive attributes of the organization, all of which could bolster employee satisfaction and productivity in the long-term.

Like client self-determination and empowerment, the strengths perspective can be seen as one of several core concepts of generalist social work practice (see McMillen, Morris, \& Sherraden, 2004; Poulin, 2009). The EPAS (CSWE, 2015) asserts that the generalist practitioner will "recognize, support, and build on the strengths and resiliency of all human beings" (p. 11). It is important to note that although the strengths perspective is recognized as an important aspect of client-centered practice, there is no universally accepted approach to application in practice settings (Staudt, Howard, \& Drake, 2001). Therefore, for BSW programs that want to include content on how to integrate a strengths-based perspective 
when working with clients who have experienced trauma, we propose the following: 1) help students to recognize that there is inherent resiliency that comes with having survived traumatic events, 2) emphasize that identifying strengths is most effective when there is a comprehensive and thorough assessment of the client's trauma history, biopsychosocial functioning, and social and cultural background, and 3) the identification of strengths can and should be applied to organizational processes and policies.

\section{Principle 6: Cultural Competency}

Critical to the development of client safety (principle 3), client empowerment and selfdetermination (principle 4), and the identification of strengths (principle 5), is recognizing the important role culture plays in the lives of clients who have experienced trauma. The ways in which a client expresses emotion, copes with traumatic stress, and seeks (or avoids) the support of others could all be influenced by cultural norms (NCTSN, 2007). Therefore, the start of services should always entail exploration of the client's cultural background and needs. Refugees, for example, who have experienced the effects of war and migration, may need additional time to build trust with service providers, especially if language barriers exist and there is need for an interpreter. Social workers can help clients identify the ways in which cultural norms aid or possibly restrict the expression of anger, sadness, and fear, along with how these emotions can serve to aid in the recovery from trauma. It is also important to recognize and respect a client's adherence to culturally-specific medical traditions and healing practices, and possibly find ways to incorporate such practices into more standard forms of trauma treatment (SAHMSA, 2014).

Equally important to recognizing and valuing a client's cultural background is understanding how one's own cultural background influences the helper-client relationship (Elliot et al., 2005). By exploring one's own history and culture, a deeper awareness and appreciation can develop for how life events, cultural influences, and privilege can shape one's worldview (Yan \& Wong, 2005). Such insight can aid social workers in recognizing deeply held biases that could hinder the quality of services or, even worse, re-traumatize clients.

Cultural competency is widely regarded as a crucial element for effective social work practice (Boyle \& Springer, 2001). The EPAS (CSWE, 2015) asserts that the generalist practitioner will "engage diversity in their practice and advocate for human rights and social and economic justice" (p. 11). Cultural competency can be seen as a more of a continuum of learning (Cross, 1988), and embodies a willingness to be a lifelong learner of other cultural and diverse peoples and traditions (Saunders, Haskins, \& Vasquez, 2015). We suggest BSW programs incorporate content into their curriculum that a) explores the unique relationship between culture and trauma, b) emphasizes the importance of selfreflexivity and understanding the effect one's own cultural background has on perception and attitude toward others, and c) frames cultural competency as a lifelong journey of inquiry and personal exploration. Courses on diversity, human development, and/or social work practice could all serve as ideal settings for the presentation of such content. 


\section{Principle 7: Healthy Relationships}

Creating an environment that is safe and accepting of clients who have experienced trauma (principle 3) can also enhance feelings of trust and building healthy relationships. Traumatic experiences, especially in the cases of physical, emotional, and/or sexual abuse, can have damaging effects on one's ability to trust others (Bath, 2008) and can be especially detrimental to the development of healthy attachment in children (Kinniburgh, Blaustein, Spinazzola, \& van der Kolk, 2005). Developing an environment that promotes honest, transparent, and accepting interactions can act as a model by which clients can begin to practice learning to trust again, which may benefit them when it comes time to repair damaged relationships (Elliot et al., 2005; Saakvitne, Gamble, Pearlman, \& Lev, 2000).

Social workers also need to be aware of how the effects of trauma and maladaptive forms of coping can affect families and external relationships (Conners-Burrow et al., 2013). For example, clients who have experienced substantial trauma in their past may have engaged in alcohol and/or illicit substance use and anti-social behaviors as a way of managing their trauma symptoms. As a result, clients may have alienated spouses, children, extended family, and friends, along with potentially damaging professional relationships. To provide effective treatment, social workers in direct service roles may need to assist clients in identifying ways of repairing damaged relationships and helping clients gain more external social supports, a key factor often associated with lower rates of PTSD and better treatment outcomes (Han et al., 2014; Tarrier \& Humphreys, 2003; Tsai, HarpazRotem, Pietrzak, \& Southwick, 2012; Vranceanu, Hobfoll, \& Johnson, 2007). BSW programs may want to include or emphasize content in their practice courses on the importance of relationships and social support for clients who have experienced trauma. Communication and social skills, including how to model appropriate boundaries should also be included in BSW course content.

Prescott and colleagues (2008) underscore the importance of providing opportunities for clients to obtain peer support, especially from other clients who have experienced similar traumatic experiences. These interactions can engender opportunities for clients to "gather, educate and organize for action can decrease isolation, generate accountability among the group, increase self-esteem and awareness of how personal experiences of violence and loss fit within a larger socio-political context" (p. 34). The idea of peer support as essential to the recovery from trauma is echoed in numerous trauma-informed frameworks (see Bloom \& Sreedhar, 2008; Elliot et al., 2005; SAHMSA, 2014).

BSW programs may consider including content that emphasizes the importance of the worker-client relationship for both its therapeutic benefit to the client and its ability to serve as a model for future relationships. Furthermore, practice courses could provide students methods for modeling specific social skills, which may enhance students' feelings of selfefficacy when working with clients who have experienced trauma. Finally, we recommend providing instruction on the importance of peer support and the need for identifying ways in which organizations can develop or modify existing processes or policies to allow clients to safely interact and provide support to one another. 


\section{Principle 8: Emotional Regulation}

As discussed in principle 1, trauma-affected clients experience a myriad of symptoms, many of which can hinder emotional regulatory capacities. Trauma can create a sense of disconnectedness from one's own emotional experiences (Kinniburgh et al., 2005), which can lead trauma survivors to not recognize when they are being triggered and/or experiencing high levels of stress. Consequently, the feeling of being emotionally overwhelmed can be perceived as occurring suddenly, which may (and often does) result in individuals engaging in maladaptive responses and/or coping behaviors. Furthermore, consistently feeling unsafe and being emotionally overwhelmed can be especially damaging to children's development (NCTSN, 2007). Thus, an essential component of trauma recovery includes the development of emotion regulation.

The ways in which clients learn to manage stress and cope with negative emotions varies widely across trauma-specific intervention approaches. Yet, at the core of these methods are three fundamental goals for emotional self-regulation that includes the development of 1) affect awareness, which is the ability to identify one's own emotional and physical feelings, 2) affect expression, which is the ability to express negative internal states in a safe and controlled manner, and 3) affect modulation, which is the ability to recognize negative emotional experiences and engage in coping activities that can aid in the return to a comfortable state of arousal (Kinniburgh et al., 2005).

Working to build emotion regulation skills in clients who have experienced trauma, in many service environments, may be seen as an activity that is best suited for graduate-level clinical personnel. In such instances, BSWs can act as supporting agents to clinicians by helping to remind and reinforce the use of these skills with their clients. This dual support may enhance the clients' feelings of safety and support, and may serve to encourage them to engage in more difficult aspects of therapy. However, not every service organization will have clinical staff available, nor may it be the role of the agency to provide direct mental health services. Further, BSWs often serve in a direct service capacity in agencies providing services to adults and children in group treatment settings, providing remedial or behavioral health services, social skills training, parent education classes, support groups and afterschool or day treatment programs. In these environments, BSWs play a direct role in helping clients build emotion regulation and problem-solving skills. Therefore, it is recommended that BSW programs provide knowledge and skills on how to build emotion regulation capacities in clients who have experienced trauma.

BSW programs may consider including content that reviews benefits of developing emotional regulations skills in clients who have experienced trauma, especially if those clients are actively working toward processing trauma with graduate-level clinicians. Practice courses that provide opportunities for in-class demonstrations and role-play practice on skills that can help with emotional regulation may promote a sense of competency for students who plan to work with client populations that have frequent exposure to trauma in their field placements. 


\section{Principle 9: Self-Care}

Trauma education also has relevance to understanding and addressing work-related stress, burnout, and organizational trauma (Dane, 2000; Trippany, Kress, \& Wilcoxon, 2004). Some research findings suggest that trauma education may be of even greater relevance to preparing bachelor's level social workers for practice. Dalton (2001) found that social workers with master's degrees exhibited lower levels of secondary traumatic stress than bachelor's level social workers. This difference that may be due to training in graduate programs that includes information on client empowerment, self-care, and recognizing maladaptive processes that may be less emphasized in BSW programs. Younger and less experienced social workers may be less skilled in effectively managing work-related stress and more vulnerable to direct and indirect exposure to trauma (Neumann \& Gamble, 1995). It is not uncommon for social workers to work with clients who engage in aggressive and violent behavior or to work in crime-ridden, high risk communities placing them at heightened risk for victimization. Yet many organizations do not have formal policies or practices related to dealing with work-related victimization and violence (Bureau of Labor Statistics, 2006). Many incidents go unreported due to beliefs that reporting will not be of benefit or fears that an incident will be considered the result of negligence or poor job performance (Bloom, 2010). In some organizations, victimization by clients is viewed as part of the job and is a normalized into the culture. Students who are knowledgeable in the tenets of trauma-informed care can apply them to assess whether organizational practices and policies ensure physical and emotional safety and employee well-being.

Providing BSW students with introductory knowledge on the effects of secondary and vicarious trauma can strengthen their ability to recognize the sources, processes, and symptoms associated with trauma. Furthermore, educators can help them to work more effectively in organizations by engaging in practice behaviors that contribute to healthy organizational environments, including knowing when and how to practice self-care and provide peer support to co-workers who may be dealing with traumatic stress (Bell et al., 2003). In addition to classroom teaching, students can gain experience applying skills during their field placements, for instance, reviewing organizational procedures and policies and assessing them from a trauma-informed perspective. Teaching students basic skills they can apply to respond to work-related stress may help reduce burn out, vicarious trauma and symptoms of traumatic stress which, in turn, promotes improved organizational functioning and more effective practice with clients.

\section{Conclusion}

The prevalence of traumatization across the general population, the deleterious impact of traumatic exposure, and the high rate of service use among those who have been traumatized, has prompted many schools of social work to start incorporating trauma content into their programing. This can take the form of specialized programs (e.g., CCCT), electives, or continuing education courses. These offerings frequently have a clinical emphasis, and are often considered "advanced" or "specialized" trainings. Thus, trauma content is most often presented at the MSW level. Unfortunately, there has yet to be a push for trauma training to be included at the BSW level. The aim of this paper was to present 
guiding principles that educators could use to infuse within the generalist perspective of the BSW curriculum. In doing so, we hope to have demonstrated that the scope of traumatic studies does not have be relegated to the presentation of only clinical material. Rather, trauma training can include work with individuals, agencies/organizations, and communities.

We echo the statement made by Courtois and Gold (2009): "the territory of trauma practice can only be adequately mastered if training in trauma is grounded in the fundamental and generalist curriculum of a profession" (p. 18). We call for the field of social work to start viewing the study of trauma as spanning both generalist and advanced domains of social work practice. Only then will our field be able to provide truly comprehensive and adequate services and treatment to those who have experienced trauma and are suffering from its effects.

\section{References}

Abrams, J., \& Shapiro, M. (2014). Teaching trauma theory and practice in MSW programs: A clinically focused, case-based method. Clinical Social Work Journal, 42(4), 408-418. doi: https://doi.org/10.1007/s10615-013-0472-z

Audergon, A. (2004). Collective trauma: The nightmare of history. Psychotherapy and Politics International, 2, 16-31. doi: https://doi.org/10.1002/ppi.67

Azeem, M. W., Aujla, A., Rammerth, M., Binsfeld, G., \& Jones, R. B. (2011). Effectiveness of six core strategies based on trauma informed care in reducing seclusions and restraints at a child and adolescent psychiatric hospital. Journal of Child and Adolescent Psychiatric Nursing, 24(1), 11-15. doi: https://doi.org/10.1111/j.1744-6171.2010.00262.x

Bath, H. (2008). The three pillars of trauma-informed care. Reclaiming Children and Youth, 17(3), 1-5. Retrieved from https://s3-us-west2.amazonaws.com/cxl/backup/prod/cxl/gklugiewicz/media/507188fa-30b7-8fd4aa5f-ca6bb629a442.pdf

Bell, H., Kulkarni, S., \& Dalton, L. (2003). Organizational prevention of vicarious trauma. Families in Society: The Journal of Contemporary Social Services, 84(4), 463-470. doi: https://doi.org/10.1606/1044-3894.131

Bloom, S. L. (2010). Organizational stress and trauma-informed services. In B. L. Leven \& M. A. Becker (Eds.), A public health perspective of women's mental health (pp. 295-311). New York: Springer. doi: https://doi.org/10.1007/978-1-4419-1526-9_15

Bloom, S. L., \& Sreedhar, S. Y. (2008). The sanctuary model of trauma-informed organizational change. Reclaiming Children and Youth, 17(3), 48-53.

Borckardt, J. J., Madan, A., Grubaugh, A. L., Danielson, C. K., Pelic, C. G., Hardesty, S. J., ... \& Frueh, B. C. (2011). Systematic investigation of initiatives to reduce seclusion and restraint in a state psychiatric hospital. Psychiatric Services, 62(5), 477-483. 
Boyle, D. P., \& Springer, A. (2001). Toward a cultural competence measure for social work with specific populations. Journal of Ethnic and Cultural Diversity in Social Work, 9(3-4), 53-71. doi: https://doi.org/10.1300/J051v09n03_03

Breckenridge, J., \& James, K. (2010). Educating social work students in multifaceted interventions for trauma. Social Work Education, 29(3), 259-275. doi: https://doi.org/10.1080/02615470902912250

Briere, J. (2005). Trauma symptom checklist for young children. Odessa, FL: Psychological Assessment Resources, Inc. Retrieved July, 2, 2012 from http://www4.parinc.com/Products/Product.aspx?ProductID=TSCYC

Breslau, N., Kessler, R. C., Chilcoat, H. D., Schultz, L. R., Davis, G. C., \& Andreski, P. (1998). Trauma and posttraumatic stress disorder in the community: The 1996 Detroit Area Survey of Trauma. Archives of General Psychiatry, 55(7), 626-632. doi: https://doi.org/10.1001/archpsyc.55.7.626

Bureau of Labor Statistics. (2006). News - Survey of workplace violence prevention, 2005. Washington, DC: United States Department of Labor. Retrieved from http://www.bls.gov/iif/oshwc/osnr0026.pdf

Bussey, M. C. (2008). Trauma response and recovery certificate program: Preparing students for effective practice. Journal of Teaching in Social Work, 28(1-2), 117-144. doi: https://doi.org/10.1080/08841230802179118

Carello, J., \& Butler, L. D. (2014). Potentially perilous pedagogies: Teaching trauma is not the same as trauma-informed teaching. Journal of Trauma \& Dissociation, 15(2), 153-168. doi: https://doi.org/10.1080/15299732.2014.867571

Carello, J., \& Butler, L. D. (2015). Practicing what we teach: Trauma-informed educational practice. Journal of Teaching in Social Work, 35(3), 262-278. doi: https://doi.org/10.1080/08841233.2015.1030059

Cohen, J. A., Mannarino, A. P., Berliner, L., \& Deblinger, E. (2000). Trauma-focused cognitive behavioral therapy for children and adolescents: An empirical update. Journal of Interpersonal Violence, 15(11), 1202-1223. doi: https://doi.org/10.1177/088626000015011007

Conners-Burrow, N. A., Kramer, T. L., Sigel, B. A., Helpenstill, K., Sievers, C., \& McKelvey, L. (2013). Trauma-informed care training in a child welfare system: Moving it to the front line. Children and Youth Services Review, 35(11), 1830-1835. doi: https://doi.org/10.1016/j.childyouth.2013.08.013

Conradi, L., Wherry, J., \& Kisiel, C. (2011). Linking child welfare and mental health using trauma-informed screening and assessment practices. Child Welfare, 90, 129147.

Copeland, W. E., Keeler, G., Angold, A., \& Costello, E. J. (2007). Traumatic events and posttraumatic stress in childhood. Archives of General Psychiatry, 64, 577-584. doi: https://doi.org/10.1001/archpsyc.64.5.577 
Council on Social Work Education [CSWE]. (2012). Advanced social work practice in trauma. Alexandria, VA: Author. Council on Social Work Education [CSWE]. (2008). Educational policy and accreditation standards [EPAS]. Alexandria, VA: Commission on Accreditation, CSWE.

Council on Social Work Education [CSWE]. (2015). Educational policy and accreditation standards [EPAS]. Alexandria, VA: Commission on Accreditation, CSWE.

Courtois, C. A. (2002). Traumatic stress studies: The need for curricula inclusion. Journal of Trauma Practice, 1(1), 33-57. doi: https://doi.org/10.1300/J189v01n01_03

Courtois, C. A., \& Gold, S. N. (2009). The need for infusion of psychological trauma in the professional curriculum: A call to action. Psychological Trauma, Research, Practice, and Policy, 1(1), 3-23. doi: https://doi.org/10.1037/a0015224

Covington, S. S., Burke, C., Keaton, S., \& Norcott, C. (2008). Evaluation of a traumainformed and gender-responsive intervention for women in drug treatment. Journal of Psychoactive Drugs, 40(5), 387-398. doi: https://doi.org/10.1080/02791072.2008.10400666

Cross, T. (1988). Services to minority populations: Cultural competence continuum. Focal Point, 3, 1-4.

Dalton, L. E. (2001). Secondary traumatic stress and Texas social workers. Unpublished doctoral dissertation, The University of Texas at Arlington, Arlington, TX.

Dane, B. (2000). Child welfare workers: An innovative approach for interacting with secondary trauma. Journal of Social Work Education, 36, 27-38.

Dane, B. (2002). Duty to inform: Preparing social work students to understand vicarious traumatization. Journal of Teaching in Social Work, 22(3-4), 3-20. doi: https://doi.org/10.1300/J067v22n03_02

de Arellano, M. A., Lyman, D. R. Jobe-Shields, L., George, P., Dougherty, R. H., Daniels, A. M.,...Delphin-Rittmon, M. E. (2014). Trauma-focused cognitive behavioral therapy: Assessing the evidence. Psychiatric Services, 65(5), 591-602. doi: https://doi.org/10.1176/appi.ps.201300255

Didham, S., Dromgole, L., Csiernik, R., Karley, M. L., \& Hurley, D. (2011). Trauma exposure and the social work practicum. Journal of Teaching in Social Work, 31, 523-537. doi: https://doi.org/10.1080/08841233.2011.615261

Dong, M., Giles, W. H., Felitti, V. J., Dube, S. R., Williams, J. E., Chapman, D. P., \& Anda, R. F. (2004). Insights into causal pathways for ischemic heart disease adverse childhood experiences study. Circulation, 110(13), 1761-1766. doi: https://doi.org/10.1161/01.CIR.0000143074.54995.7F

Dutton, M. A., \& Goodman, L. A. (2005). Coercion in intimate partner violence: Toward a new conceptualization. Sex Roles, 52(11-12), 743-756. doi: https://doi.org/10.1007/s11199-005-4196-6 
Ehlers, A., Bisson, J., Clark, D. M., Creamer, M., Pilling, S., Richards, D.,...Yule, W. (2010). Do all psychological treatments really work the same in posttraumatic stress disorder? Clinical Psychology Review, 30, 269-276. doi: https://doi.org/10.1016/j.cpr.2009.12.001

Elhai, J. D., North, T. C., \& Frueh, B. C. (2005). Health service use predictors among trauma survivors: a critical review. Psychological Services, 2(1), 3-19. doi: https://doi.org/10.1037/1541-1559.2.1.3

Elliot, D. E., Bjelajac, P., Fallot, R. D., Markoff, L. S., \& Reed, B. G. (2005). Traumainformed or trauma-denied: Principles and implementation of trauma-informed services for women. Journal of Community Psychology, 33, 461-477. doi: https://doi.org/10.1002/jcop.20063

Etherington, K. (2000). Supervising counsellors who work with survivors of childhood sexual abuse. Counselling Psychology Quarterly, 13(4), 377-389. doi: https://doi.org/10.1080/713658497

Fallot, R. D., \& Harris, M. (2001). A trauma-informed approach to screening and assessment. New Directions for Mental Health Services, 2001(89), 23-31. doi: https://doi.org/10.1002/yd.23320018904

Farchi, M., Cohen, A., \& Mosek, A. (2014). Developing specific self-efficacy and resilience as first responders among students of social work and stress and trauma studies. Journal of Teaching in Social Work, 34(2), 129-146. doi: https://doi.org/10.1080/08841233.2014.894602

Felitti, V. J., Anda, R. F., Nordenberg, D., Williamson, D. F., Spitz, A. M., Edwards, V., ...Marks, J. S. (1998). Relationship of childhood abuse and household dysfunction to many of the leading causes of death in adults: The Adverse Childhood Experiences (ACE) Study. American Journal of Preventive Medicine, 14(4), 245-258. doi: https://doi.org/10.1016/S0749-3797(98)00017-8

Frans, Ö., Rimmö, P. A., Åberg, L., \& Fredrikson, M. (2005). Trauma exposure and posttraumatic stress disorder in the general population. Acta Psychiatrica Scandinavica, 111(4), 291-299. https://doi.org/10.1111/j.1600-0447.2004.00463.x

Gatz, M., Brown, V., Hennigan, K., Rechberger, E., O'Keefe, M., Rose, T., \& Bjelajac, P. (2007). Effectiveness of an integrated, trauma-informed approach to treating women with co-occurring disorders and histories of trauma: The Los Angeles site experience. Journal of Community Psychology, 35(7), 863-878. doi: https://doi.org/10.1002/jcop.20186

Gershuny, B. S., \& Thayer, J. F. (1999). Relations among psychological trauma, dissociative phenomena, and trauma-related distress: A review and integration. Clinical Psychology Review, 19(5), 631-657. doi: https://doi.org/10.1016/S0272-7358(98)00103-2

Guarino, K., Rubin, L., \& Bassuk, E.L. (2007). Violence and trauma in the lives of homeless families. In E. Carll (Ed). Trauma Psychology. (pp. 231-258). Westport: 
Praeger Publishers.

Guarino, K., Soares, P., Konnath, K., Clervil, R., and Bassuk, E. (2009). Traumainformed organizational toolkit. Rockville, MD: Center for Mental Health Services, Substance Abuse and Mental Health Services Administration, and the Daniels Fund, the National Child Traumatic Stress Network, and the W.K. Kellogg Foundation. Retrieved from http://www.nada.org.au/media/14607/tictoolkitforhomelessservicesusa.pdf

Han, S. C., Castro, F., Lee, L. O., Charney, M. E., Marx, B. P., Brailey, K., ...Vasterling, J. J. (2014). Military unit support, postdeployment social support, and PTSD symptoms among active duty and National Guard soldiers deployed to Iraq. Journal of Anxiety Disorders, 28(5), 446-453. doi: https://doi.org/10.1016/j.janxdis.2014.04.004

Harris, M., \& Fallot, R. D. (2001). Designing trauma-informed addictions services. New Directions for Mental Health Services, 2001(89), 57-73. doi: https://doi.org/10.1002/yd.23320018907

Hopper, E. K., Bassuk, E. L., \& Olivet, J. (2009). Shelter from the storm: Traumainformed care in homelessness services settings. The Open Health Services and Policy Journal, 2, 131-151.

Huckshorn, K. A. (2004). Reducing seclusion \& restraint use in mental health settings: Core strategies for prevention. Journal of Psychosocial Nursing and Mental Health Services, 42(9), 22-33.

Huckshorn, K. A., CAP, I., \& Director, N. T. A. C. (2005). Six core strategies to reduce the use of seclusion and restraint planning tool. National Association of State Mental Health Program Directors. Available at: https://www.nasmhpd.org/sites/default/files/Consolidated\%20Six\%20Core\%20Strat egies\%20Document.pdf

Jennings, A. (2008). Models for developing trauma-informed behavioral health systems and trauma-specific services. Alexandria,VA: National Center for Trauma-Informed Care. Retrieved from http://www.ct.gov/dmhas/lib/dmhas/trauma/TraumaModels.pdf

Kahn, W. A. (2003). The revelation of organizational trauma. The Journal of Applied Behavioral Science, 39(4), 364-380. doi: https://doi.org/10.1177/0021886303261954

Kilpatrick, D. G., Resnick, H. S., Milanak, M. E., Miller, M. W., Keyes, K. M., \& Friedman, M. J. (2013). National estimates of exposure to traumatic events and PTSD prevalence using DSM-IV and DSM-5 criteria. Journal of Traumatic Stress, 26, 537-547. doi: https://doi.org/10.1002/jts.21848

Kinniburgh, K., Blaustein, M., Spinazzola, J., \& van der Kolk, B. (2005). Attachment, self-regulation and competency: A comprehensive intervention framework for children with complex trauma. Psychiatric Annals, 35(5), 424-430. 
Kirst-Ashman, K., \& Hull Jr., G. (2014). Brooks/Cole empowerment series: Generalist practice with organizations and communities $\left(6^{\text {th }} \mathrm{ed}\right.$.). Boston: Cengage Learning.

Kisiel, C., Fehrenbach, T., Small, L., \& Lyons, J. S. (2009). Assessment of complex trauma exposure, responses, and service needs among children and adolescents in child welfare. Journal of Child \& Adolescent Trauma, 2(3), 143-160. doi: https://doi.org/10.1080/19361520903120467

Knight, C. (2010). Indirect trauma in the field practicum: Secondary traumatic stress, vicarious trauma, and compassion fatigue among social work students and their field instructors. Journal of Baccalaureate Social Work, 15, 31-52.

Ko, S. J., Ford, J. D., Kassam-Adams, N., Berkowitz, S. J., Wilson, C. Wong, M.,...Layne, C. M. (2008). Creating trauma-informed systems: Child welfare, education, first responders, health care, juvenile justice. Professional Psychology: Research and Practice, 39, 396-404. doi: https://doi.org/10.1037/0735-7028.39.4.396

Layne, C. M., Ippen, C. G., Strand, V., Stuber, M., Abramovitz, R., Reyes, G., ...Pynoos, R. (2011). The Core Curriculum on Childhood Trauma: A tool for training a traumainformed workforce. Psychological Trauma: Theory, Research, Practice, and Policy, 3(3), 243-252. https://doi.org/10.1037/a0025039

Layne, C. M., Strand, V., Popescu, M., Kaplow, J. B., Abramovitz, R., Stuber, M., ...Pynoos, R. S. (2014). Using the core curriculum on childhood trauma to strengthen clinical knowledge in evidence-based practitioners. Journal of Clinical Child \& Adolescent Psychology, 43(2), 286-300. doi: https://doi.org/10.1080/15374416.2013.865192

Levenson, J. S., Willis, G. M., \& Prescott, D. S. (2014). Adverse Childhood Experiences in the lives of male sex offenders: Implications for trauma-informed care. Sexual Abuse: A Journal of Research and Treatment, 28(4), 340-359. doi: http://dx.doi.org/10.1177/1079063214535819

Marlowe, J., \& Adamson, C. (2011). Teaching trauma: Critically engaging a troublesome term. Social Work Education, 30(6), 623-634. doi: https://doi.org/10.1080/02615479.2011.586559

McKenzie-Mohr, S. (2004). Creating space for radical trauma theory in generalist social work education. Journal of Progressive Human Services, 15(2), 45-55.

McKenzie-Mohr, S., Coates, J., \& McLeod, H. (2012). Responding to the needs of youth who are homeless: Calling for politicized trauma-informed intervention. Children and Youth Services Review, 34(1), 136-143. doi: https://doi.org/10.1016/j.childyouth.2011.09.008

McManus, H. H., \& Thompson, S. J. (2008). Trauma among unaccompanied homeless youth: The integration of street culture into a model of intervention. Journal of Aggression, Maltreatment \& Trauma, 16(1), 92-109. doi: https://doi.org/10.1080/10926770801920818 
McMillen, J. C., Morris, L., \& Sherraden, M. (2004). Ending social work's grudge match: Problems versus strengths. Families in Society: The Journal of Contemporary Social Services, 85(3), 317-325. doi: https://doi.org/10.1606/1044-3894.1492

Miley, K.K., O'Melia, M., \& DuBois, B. (2013). Generalist social work practice: An empowering approach (7th ed.). Boston: Allyn \& Bacon.

Miller, M. (2001). Creating a safe frame for learning: Teaching about trauma and trauma treatment. Journal of Teaching in Social Work, 21(3/4), 159-176. doi: https://doi.org/10.1300/J067v21n03_12

National Child Traumatic Stress Network, Child Welfare Collaborative Group, \& California Social Work Education Center [NCTSN]. (2007). Creating traumainformed child-serving systems. NCTSN Service Systems Briefs, 1(1). URL: http://www.nctsnet.org/nctsn assets/pdfs/Service Systems Brief v1 v1.pdf

Najavits, L. M., Sonn, J., Walsh, M., \& Weiss, R. D. (2004). Domestic violence in women with PTSD and substance abuse. Addictive Behaviors, 29(4), 707-715. doi: https://doi.org/10.1016/j.addbeh.2004.01.003

Neumann, D. A., \& Gamble, S. J. (1995). Issues in the professional development of psychotherapists: Countertransference and vicarious traumatization in the new trauma therapist. Psychotherapy: Theory, Research, Practice, Training, 32(2), 341347. doi: https://doi.org/10.1037/0033-3204.32.2.341

Nytagodien, R., \& Neal, A. (2004). Collective trauma, apologies, and the politics of memory. Journal of Human Rights, 3, 465-475. doi: https://doi.org/10.1080/1475483042000299714

O'Halloran, M.S., \& O'Halloran, T. (2001). Secondary traumatic stress in the classroom: Ameliorating stress in graduate students. Teaching of Psychology, 28(2), 92-97. doi: https://doi.org/10.1207/S15328023TOP2802_03

Poulin, J. (2009). Strengths-based generalist practice: A collaborative approach. Boston: Cengage Learning.

Prescott, L., Soares, P., Konnath, K., \& Bassuk, E. (2008). A long journey home: A guide for creating trauma-informed services for mothers and children experiencing homelessness. Rockville, MD: Center for Mental Health Services, Substance Abuse and Mental Health Services Administration. Retrieved from http://brightspaces.org/wp-content/uploads/Trauma-Informed-Services-Guide.pdf

Regan, K. (2010). Trauma informed care on an inpatient pediatric psychiatric unit and the emergence of ethical dilemmas as nurses evolved their practice. Issues in Mental Health Nursing, 31(3), 216-222.

Rubin, A., \& Springer, D. W. (2009). Treatment of traumatized adults and children: A clinician's guide to evidence-based practice. Hoboken, NJ: Wiley. 
Saakvitne, K. W., Gamble, S., Pearlman, L. A., \& Lev, B. T. (2000). Risking connection: A training curriculum for working with survivors of childhood abuse. Brooklandville, MD: The Sidran Press.

Saunders, J. A., Haskins, M., \& Vasquez, M. (2015). Cultural competence: A journey to an elusive goal. Journal of Social Work Education, 51(1), 19-34.

Substance Abuse and Mental Health Services Administration. (2014). SAMHSA's Concept of Trauma and Guidance for a Trauma-Informed Approach (HHS Pub. No. (SMA) 14-4884). Rockville, MD: Author.

Schneider, S. J., Grilli, S. F., \& Schneider, J. R. (2013). Evidence-based treatments for traumatized children and adolescents. Current Psychiatry Reports, 15(1), 1-9. doi: https://doi.org/10.1007/s11920-012-0332-5

Shannon, P. J., Simmelink, J., Im, H., Becher, E., \& Crook-Lyon, R. E. (2014). Developing self-care practices in a trauma-treatment course. Journal of Social Work Education, 50, 440-453.

Solomon, S. D., \& Davidson, J. R. (1997). Trauma: Prevalence, impairment, service use, and cost. Journal of Clinical Psychiatry, 58, 5-11.

Stein, M. B., Walker, J. R., Hazen, A. L., \& Forde, D. R. (1997). Full and partial posttraumatic stress disorder: Findings from a community survey. American Journal of Psychiatry, 154(8), 1114-1119. doi: https://doi.org/10.1176/ajp.154.8.1114

Strand, V. C., Abramovitz, R., Layne, C. M., Robinson, H., \& Way, I. (2014). Meeting the critical need for trauma education in social work: A problem-based learning approach. Journal of Social Work Education, 50(1), 120-135.

Staudt, M., Howard, M. O., \& Drake, B. (2001). The operationalization, implementation, and effectiveness of the strengths perspective: A review of empirical studies. Journal of Social Service Research, 27(3), 1-21. doi: https://doi.org/10.1300/J079v27n03_01

Tarrier, N., \& Humphreys, A. L. (2003). PTSD and the social support of the interpersonal environment: The development of social cognitive behavior therapy. Journal of Cognitive Psychotherapy, 17(2), 187-198. doi: https://doi.org/10.1891/jcop.17.2.187.57440

Tsai, J., Harpaz-Rotem, I., Pietrzak, R. H., \& Southwick, S. M. (2012). The role of coping, resilience, and social support in mediating the relation between PTSD and social functioning in veterans returning from Iraq and Afghanistan. Psychiatry, 75(2), 135-149. doi: https://doi.org/10.1521/psyc.2012.75.2.135

Trippany, R. L., Kress, V. E. W., \& Wilcoxon, S. A. (2004). Preventing vicarious trauma: What counselors should know when working with trauma survivors. Journal of Counseling \& Development, 82, 31-37. doi: https://doi.org/10.1002/j.15566678.2004.tb00283.x 
Turner, H. A., Finkelhor, D., \& Ormrod, R. (2010). Poly-victimization in a national sample of children and youth. American Journal of Preventive Medicine, 38, 323330. doi: https://doi.org/10.1016/j.amepre.2009.11.012

Vrana, S., \& Lauterbach, D. (1994). Prevalence of traumatic events and post-traumatic psychological symptoms in a nonclinical sample of college students. Journal of Traumatic Stress, 7(2), 289-302. doi: https://doi.org/10.1002/jts.2490070209

Vranceanu, A. M., Hobfoll, S. E., \& Johnson, R. J. (2007). Child multi-type maltreatment and associated depression and PTSD symptoms: The role of social support and stress. Child Abuse \& Neglect, 31(1), 71-84. doi: https://doi.org/10.1016/j.chiabu.2006.04.010

Yan, M. C., \& Wong, Y. L. R. (2005). Rethinking self-awareness in cultural competence: Toward a dialogic self in cross-cultural social work. Families in Society: The Journal of Contemporary Social Services, 86(2), 181-188. doi: https://doi.org/10.1606/1044$\underline{3894.2453}$

Author note: Address correspondence to: Matthew Vasquez, Department of Social Work, University of Northern Iowa, Sabin 235, Cedar Falls, IA 50614 matthew.vasquez@uni.edu 